\title{
Electron Microscopy of Herpes Simplex Virus
}

\author{
III. Effect of Hydroxyurea
}

\author{
S. NII, ${ }^{1}$ H. S. ROSENKRANZ, C. MORGAN, AND H. M. ROSE \\ Department of Microbiology, College of Physicians and Surgeons, Columbia University, \\ New York, New York 10032
}

Received for publication 26 July 1968

\begin{abstract}
The effect of hydroxyurea on the development of herpes virus is mediated through its inhibitory action on deoxyribonucleic acid (DNA) synthesis. Concentrations of the drug that suppress the production of infectious virus cause typical developmental anomalies: failure in formation of the normally dense cores or "complete" viral particles, and either faulty or no envelopment of viral capsids by membranes. The synthesis of viral capsids and virus-stimulated nuclear and cytoplasmic membranes, however, is not interrupted. Combining these results with those of time sequence experiments, the following hypotheses can be presented regarding viral development. Protein synthesis, which is characterized by capsids enclosing cores of low density, precedes DNA synthesis, which is characterized by the appearance of dense cores. Capsids with dense cores are selectively transported to the cytoplasm. Envelopment generally takes place as capsids pass from the nucleus to the cytoplasm. The process of envelopment is also selective, with the result that the majority of particles that have an envelope contain a full quota of DNA.
\end{abstract}

As part of our studies dealing with the development of herpes simplex virus, we examined the role of deoxyribonucleic acid (DNA) in viral morphogenesis. To achieve this purpose, adadvantage was taken of the properties of hydroxyurea (HU), a drug that inhibits DNA synthesis selectively in bacterial (14), plant (4), and animal cells $(3,11,17)$. In the cases of bacteriophage T4 (7) and vaccinia virus (15), it was shown that hydroxyurea-treated cells elaborated viral particles that were devoid of DNA. The drug has also been reported to block the development of other DNA viruses [e.g., Shope fibroma (1), adenovirus (6, and unpublished data) ] and African swine fever virus (S. Breese, personal communication). It should be emphasized that chemical and metabolic studies have shown that hydroxyurea does not interfere with the DNA-directed synthesis of messenger ribonucleic acid (mRNA) and of functional proteins $(13,16)$.

\section{Materials AND Methods}

Monolayer cultures of human amnion (FL) cells were infected with the Miyama strain (9) of herpes

\footnotetext{
1 Postdoctoral Fellow supported by grants from the Rockefeller Foundation, a special Lederle International Fellowship, and The Jane Coffin Childs Memorial Fund for Medical Research. Present address: The Research Institute for Microbial Diseases, Osaka University, Osaka, Japan.
}

simplex virus at a multiplicity of approximately 10 plaque-forming units per cell. After $1 \mathrm{hr}$ of exposure to the virus, the cells were washed three times with Eagle's minimal essential medium (MEM) and incubated at $37 \mathrm{C}$ in MEM supplemented with $5 \%$ calf serum, which contained $\mathrm{HU}$ at a concentration of $5 \times 10^{-2}, 1 \times 10^{-2}$, or $5 \times 10^{-3} \mathrm{M}$. Control cultures were prepared in a similar manner, but without $\mathrm{HU}$. During the first $24 \mathrm{hr}$ of incubation, samples of the control and drug-treated cultures were collected at 4-hr intervals, quick-frozen, and stored at $-30 \mathrm{C}$. For infectivity titrations, these samples were thawed at $37 \mathrm{C}$, sonically treated, and tested in tube cultures of FL cells by the end-point dilution method (expressed as $T C I D_{50}$ ), using four tubes per dilution. For electron microscopic study, the cultures were harvested at 24 and $48 \mathrm{hr}$, and the cells were prepared by the methods described in the first paper of this series (8). In several experiments, HU was added to infected cells at sufficient concentration to block virion synthesis. After incubation for 7 to $24 \mathrm{hr}$, the cells were washed and medium that was devoid of $\mathrm{HU}$ was added. The cells were collected after 8 or $17 \mathrm{hr}$ and prepared for examination in the electron microscope.

To study the effects of $\mathrm{HU}$ on the synthesis of DNA by normal and virus-infected cells, a set of bottles that contained monolayers of HeLa cells $\left(5 \times 10^{5}\right)$ was infected with $0.3 \mathrm{ml}$ of undiluted herpes simplex virus $\left(10^{7} \mathrm{TCID}_{50} / \mathrm{ml}\right)$. A second set of cultures served as controls. At the end of $1 \mathrm{hr}$, all of the cultures were washed and incubated for another hour in the presence of MEM. At this time, each of the cultures was 
supplemented with ${ }^{3} \mathrm{H}$-thymidine (final concentration, $1 \mu \mathrm{c} / \mathrm{ml}$ and $6.7 \mu \mathrm{c} / \mathrm{ml}$, respectively). At intervals, groups of cultures from each set received hydroxyurea (final concentration, $10^{-2} \mathrm{M}$; at this concentration in HeLa cells, infectious virus is not synthesized). To determine the amount of ${ }^{3} \mathrm{H}$-thymidine that was incorporated, the cells were washed with chilled 0.15 $\mathrm{M} \mathrm{NaCl}$ and then resuspended in 5\% trichloroacetic acid. After standing in the cold, the insoluble residues were collected on Munktells no. $1 \mathrm{~F}$ filter discs and washed thoroughly with cold $5 \%$ trichloroacetic acid. The dried filter discs were placed in vials that contained $10 \mathrm{ml}$ of scintillation fluid $(4 \mathrm{~g}$ of omnifluor per $1 \mathrm{~g}$ of toluene) and the radioactivity retained thereon was determined in a Tri-Carb liquid scintillation-spectrometer (Packard Instrument Co., Inc., Downer's Grove, Ill.).

An additional technique was used to determine the amount of ${ }^{3} \mathrm{H}$-thymidine incorporated into the DNA of FL cells infected with herpes simplex virus. The procedure was essentially the one described by Roizman and Roane (12). FL cells were grown in monolayers as noted above. One hr after infection, both control and infected cultures received a pulse of ${ }^{3} \mathrm{H}$-thymidine, which was repeated $4 \mathrm{hr}$ later. Some of the cultures also received $\mathrm{HU}$ (final concentration $0.01 \mathrm{M}$ ) at the time when they were given the first pulse of ${ }^{3} \mathrm{H}$-thymidine. After $20 \mathrm{hr}$, when the infected cultures showed typical cytopathic changes, the cells were harvested and washed and their DNA was isolated by a phenol-extraction procedure (12). Portions of the DNA were layered on $4.5 \mathrm{ml}$ of cesium chloride $\left(1.70 \mathrm{~g} / \mathrm{cm}^{3}\right)$ and centrifuged at 70,000 $\times \mathrm{g}$ (Spinco L-2, SW-50 rotor) for $72 \mathrm{hr}$; fractions were collected as previously described (2). The fractions were diluted with water, and trichloroacetic acid was added to a final concentration of $5 \%$. After standing at $4 \mathrm{C}$ for $30 \mathrm{~min}$, the precipitates that formed were collected on filter discs (B-10; Schleicher \& Schuell Co., Keene, N.H.) and processed as described above. The position of the peaks of radioactivity in the gradient permitted their identification as either cellular or viral DNA (12).

For fluorescence studies, HeLa cells infected for 18 hr were fixed in acetone, air-dried, and stained in the usual manner with fluorescein-conjugated antibody. The antibody, provided by $R$. A. Malmgren of the National Cancer Institute, was obtained from rabbits that had received, over a period of 4 months, 15 intracutaneous and intraperitoneal injections of virus.

\section{RESULTS}

The synthesis of infectious virus was progressively reduced by increasing concentrations of $\mathrm{HU}$ until, at $5 \times 10^{-2} \mathrm{M}$, it was completely inhibited, as shown in Fig. 1. This inhibitory action of the drug undoubtedly was the result of its interference with DNA synthesis, since, as is shown in Fig. 2 and Table 1 , a concentration of $10^{-2} \mathrm{M}$ drastically inhibited both cellular and viral DNA synthesis. The data exhibited in Fig. 2 also indicate that viral infection stimulated DNA synthe-

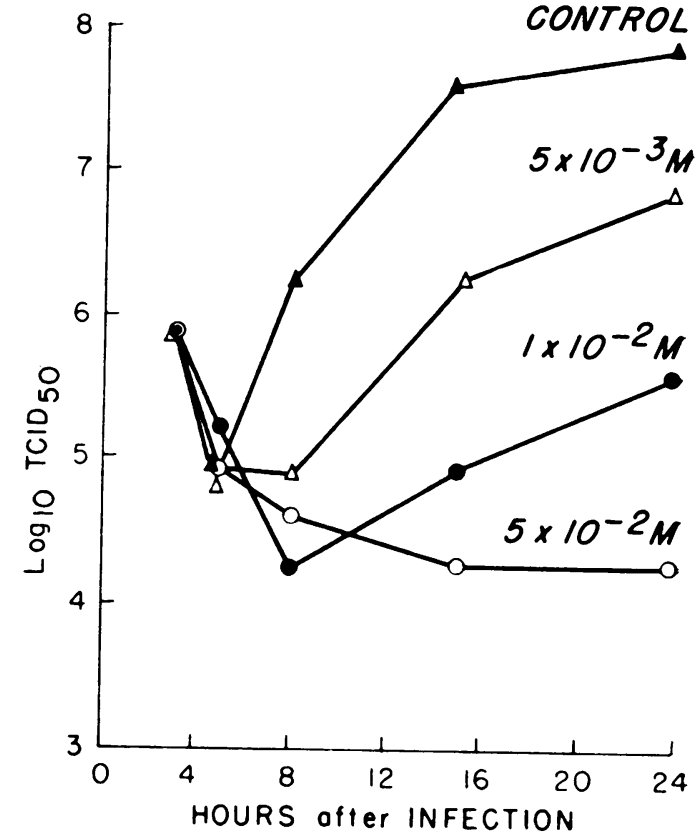

FIG. 1. Effect of differing concentrations of $H U$ on the synthesis of infectious virus in $F L$ cells.

\section{UNINFECTED INFECTED \\ CELLS \\ CELLS}

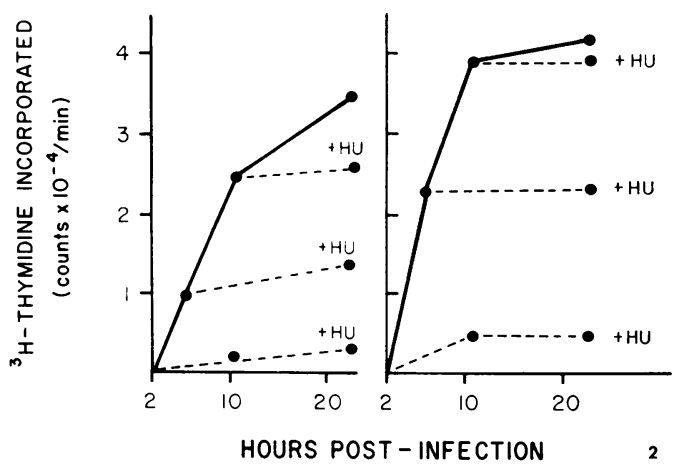

Fig. 2. Effect of hydroxyurea $\left(10^{-2} \mathrm{M}\right)$ on $D N A$ synthesis by normal and herpes simplex virus-infected HeLa cells. Symbols: solid line, uptake in the absence of $\mathrm{HU}$; broken line, uptake by $\mathrm{HU}$-treated cultures.

sis, an observation that has been made by other investigators (5). Examination by fluorescence microscopy using fluorescein-conjugated antibody showed the presence of sharply defined, bright fluorescent areas in the nuclei of the cells that were treated with hydroxyurea.

The electron microscopic appearance of virus in cells treated with $5 \times 10^{-2} \mathrm{M} \mathrm{HU}$ is illustrated in 
TABLE 1. Effect of $H U$ on DNA synthesis by uninfected and virus-infected $F L$ cells ${ }^{a}$

\begin{tabular}{l|c|c}
\hline \multicolumn{1}{c|}{ Conditions } & Type of DNA & $\begin{array}{c}\text { 3H-thymi- } \\
\text { dine incor- } \\
\text { porated } \\
\text { (counts/min } \\
\text { per peak) }\end{array}$ \\
\hline Uninfected cells & Host & 36,700 \\
Uninfected cells + HU & Host & 270 \\
Infected cells & Viral & 34,300 \\
Infected cells + HU & Viral & 1,385 \\
\hline
\end{tabular}

${ }^{a}$ DNA isolated from infected and uninfected cells was subjected to preparative cesium chloride buoyant density centrifugation. The position of the DNA in the gradient (i.e., its density) was used to determine its nature (host DNA, $1.70 \mathrm{~g} / \mathrm{cm}^{3}$; viral DNA, $1.73 \mathrm{~g} / \mathrm{cm}^{3}$ ). The radioactivity present in these bands was used to measure the amount of DNA synthesized.

Fig. 3-7. Figures 3 and 4 show parts of nuclei with capsids that contain cores of low density. In the latter micrograph, nuclear membrane reduplication is evident at the upper right. In Fig. 5, there are a few membranous structures, presumably capsids, forming in an aberrant manner within the nuclear matrix. No cores are evident. Reduplication of the nuclear membrane was occasionally observed (Fig. 4 and 6) indicating that this form of protein synthesis did occur. Virus released into the cytoplasm, however, neither possessed a dense core nor became enveloped. Figure 7 shows a characteristic cluster of intracytoplasmic capsids, some of which are empty while others contain a very small core of low density. None are enveloped.

At a drug concentration of $10^{-2} \mathrm{M}$ (Fig. 8-11), the cores and capsids often varied in size, as illustrated by Fig. 8. In Fig. 9 the cores, which are of low density, exhibit two sizes. Some capsids are only partially formed, others are complete but empty. Figure 10 shows capsids which differ in size and either are empty or contain pleomorphic cores. One capsid at the upper right, however, encloses a dense, sharply defined core. In the cytoplasm, as seen in Fig. 11, most cores were of low density, but an occasional capsid (see arrow) enclosed a dense core. A few enveloped particles were also encountered.

At a drug concentration of $5 \times 10^{-3} \mathrm{M}$, more enveloped virus was seen. Not infrequently, however, cells containing very few viral particles appeared to be actively synthesizing membranes. Figure 12 illustrates the cytoplasm of such a cell. Characteristic dense, fused membranes in a variety of configurations are evident. Some (see arrow) appear to be budding into a vacuole. No viral particles can be identified.
Figure 13 illustrates part of the cytoplasm and nucleus of a cell which had been blocked with $\mathrm{HU}$ at the time of infection. Seven hr later, the block was removed and the cells were incubated for an additional $17 \mathrm{hr}$. Numerous characteristic viral particles with dense cores and envelopes are evident. In addition, membranes closely resembling the envelope of the virus are scattered through the cytoplasm. The inset shows two extracellular viral particles with cores of low density. In this instance, the infected cells were blocked for $17 \mathrm{hr}$ and released for $8 \mathrm{hr}$. Many of the cells contained characteristic virus with dense cores.

\section{Discussion}

The results of these studies resemble those that were obtained in examining the effects of $\mathrm{HU}$ on the development of vaccinia virus (15). In both instances, it appears that certain viral proteins are produced in the absence of normal DNA synthesis. In the case of vaccinia virus, immature virus is made but it is devoid of the dense nucleoid, and maturation into the infectious virion is prevented. In the case of herpes simplex virus, the capsids form but the particles lack a dense core, and envelopment of the capsid does not occur. In both instances, fluorescence microscopy revealed the presence of viral antigen. If it is assumed that hydroxyurea behaves in this system as it does in others, the following scheme can be proposed to explain these observations. When $\mathrm{HU}$ is employed, the parental infecting DNA codes not only for early proteins but for some structural proteins (capsids) as well. Since the assembly of viral envelopes is prevented by $\mathrm{HU}$, it can be concluded that this process is regulated by progeny, rather than parental, DNA. It may then be predicted that when $\mathrm{HU}$ is removed, enveloped particles will be formed. Such indeed proved to be the case (Fig. 13).

In the normal course of development (10), the intranuclear capsids enclosing cores devoid of or deficient in DNA (and hence of low electron density) greatly exceed in number the dense cores which are presumed to have a full quota of DNA, whereas in the cytoplasm the reverse is true and nearly all the particles contain dense cores. The possibility that the capsids that enclose cores of low density disintegrate rapidly, and thus disappear, upon leaving the nucleus cannot be entirely excluded, but their repeated presence in the cytoplasm of cells treated with HU (Fig. 7 and 11) would seem to make this unlikely. One tentative explanation can be offered; namely, since cells are adept at selective transport, it is this process which accounts for passage into the cytoplasm of only one type of particle 


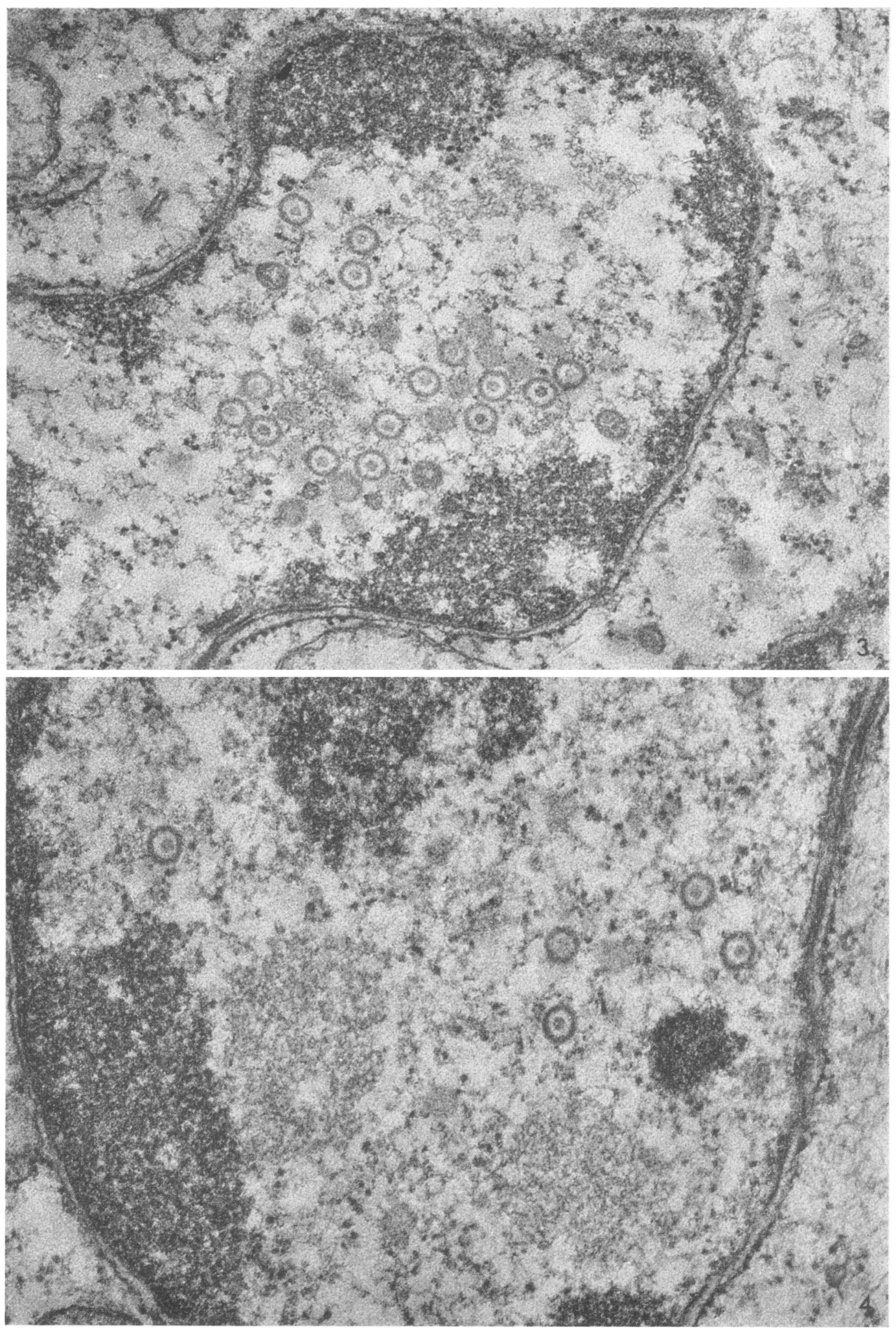

FIG. 3. Capsids with cores of low density. $5 \times 10^{-2} \mathrm{M} \mathrm{HU} . \times 54,000$.

FIG. 4. Reduplication of the nuclear membrane at upper right. $5 \times 10^{-2} \mathrm{M} \mathrm{HU} . \times 54,000$. 


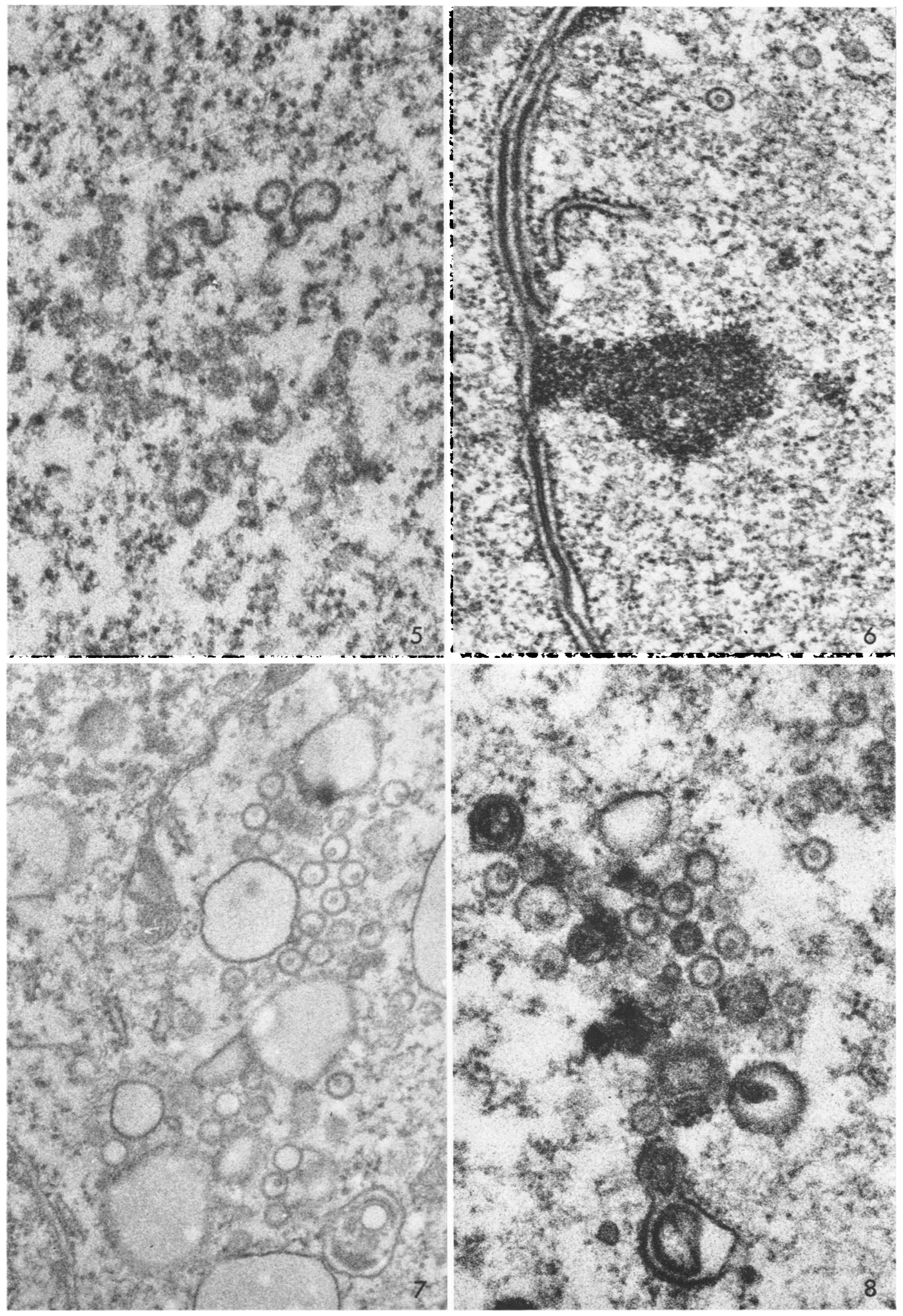

FIG. 5. Aberrant formation of capsids. $5 \times 10^{-2}$ м HU. $\times 68,000$.

FIG. 6. Reduplication of the nuclear membrane. $5 \times 10^{-2} \mathrm{M} \mathrm{HU} \times 47,000$

FIG. 7. Intracytoplasmic capsids with cores of low density. None is enveloped. $5 \times 10^{-2} \mathrm{M} \mathrm{HU} . \times 40,000$.

FIG. 8. Intranuclear cores and capsids of variable size. $10^{-2}$. $\mathrm{HU} . \times 60,000$. 


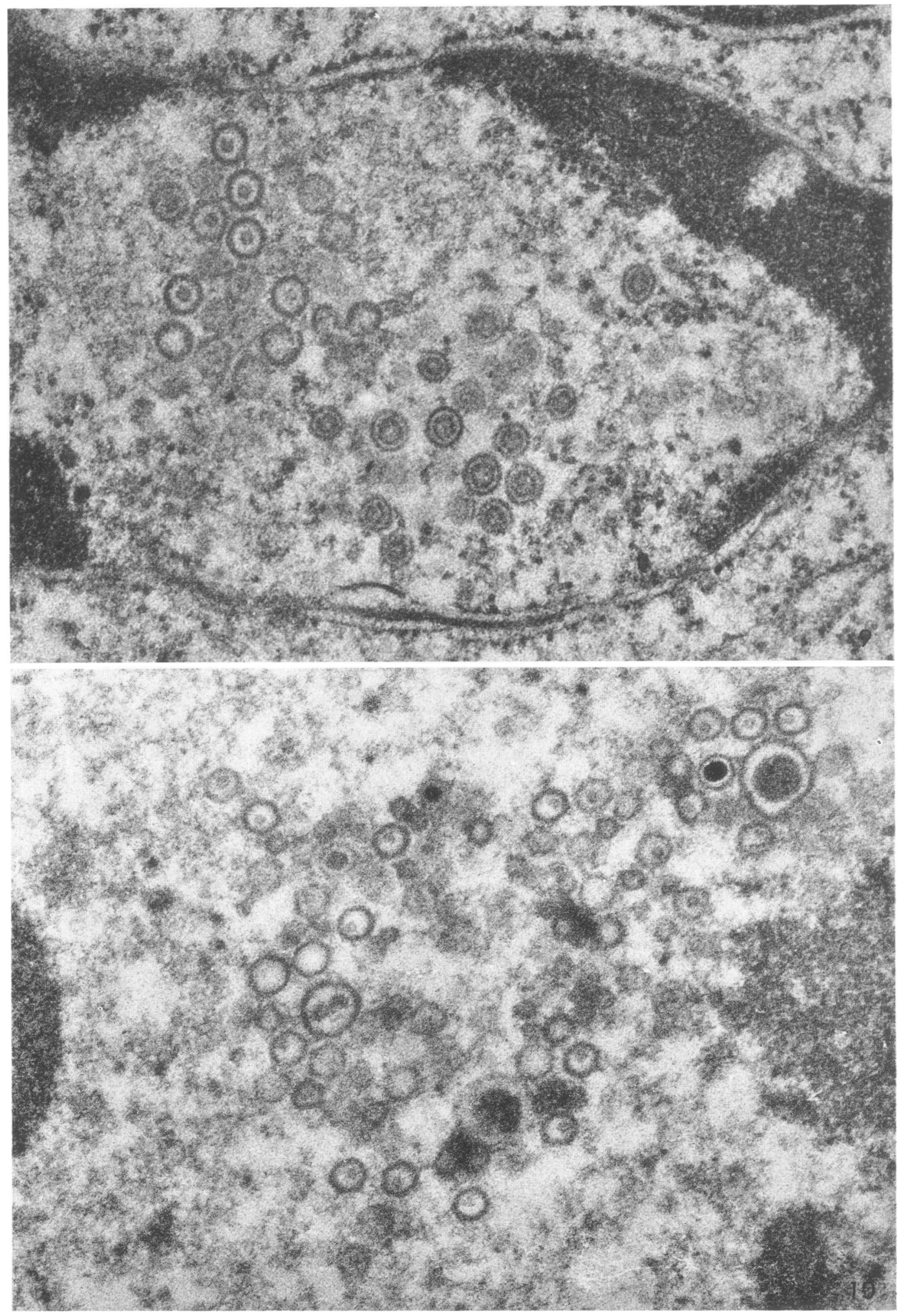

FIG. 9. Two types of cores. $10^{-2}$ M HU. $\times 55,000$.

FIG. 10. Capsids of variable size with pleomorphic cores. A dense core is visible at the upper right. $10^{-2} \mathrm{M} H$. $\times 60,000$. 


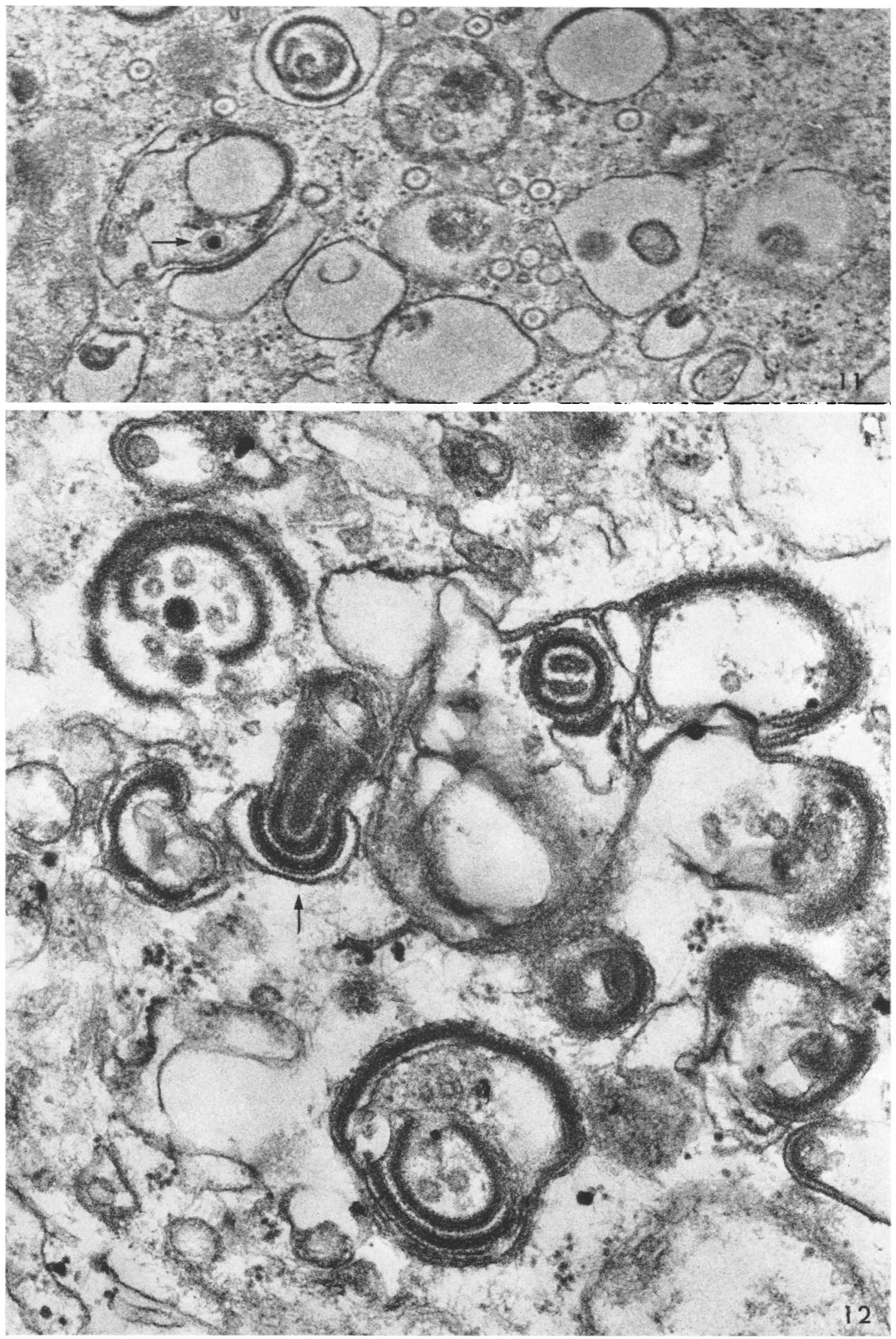

Fig. 11. Intracytoplasmic capsids with cores of low density. The arrow indicates one capsid enclosing a dense core. $10^{-2}$ : $\mathrm{HU}$. $\times 40,000$.

Fig. 12. Dense fused membranes in the cytoplasm of a cell treated with $5 \times 10^{-3}$ M HU. The arrow indicates membranes in process of budding into a vacuole. No virus can be identified. $\times 65,000$. 


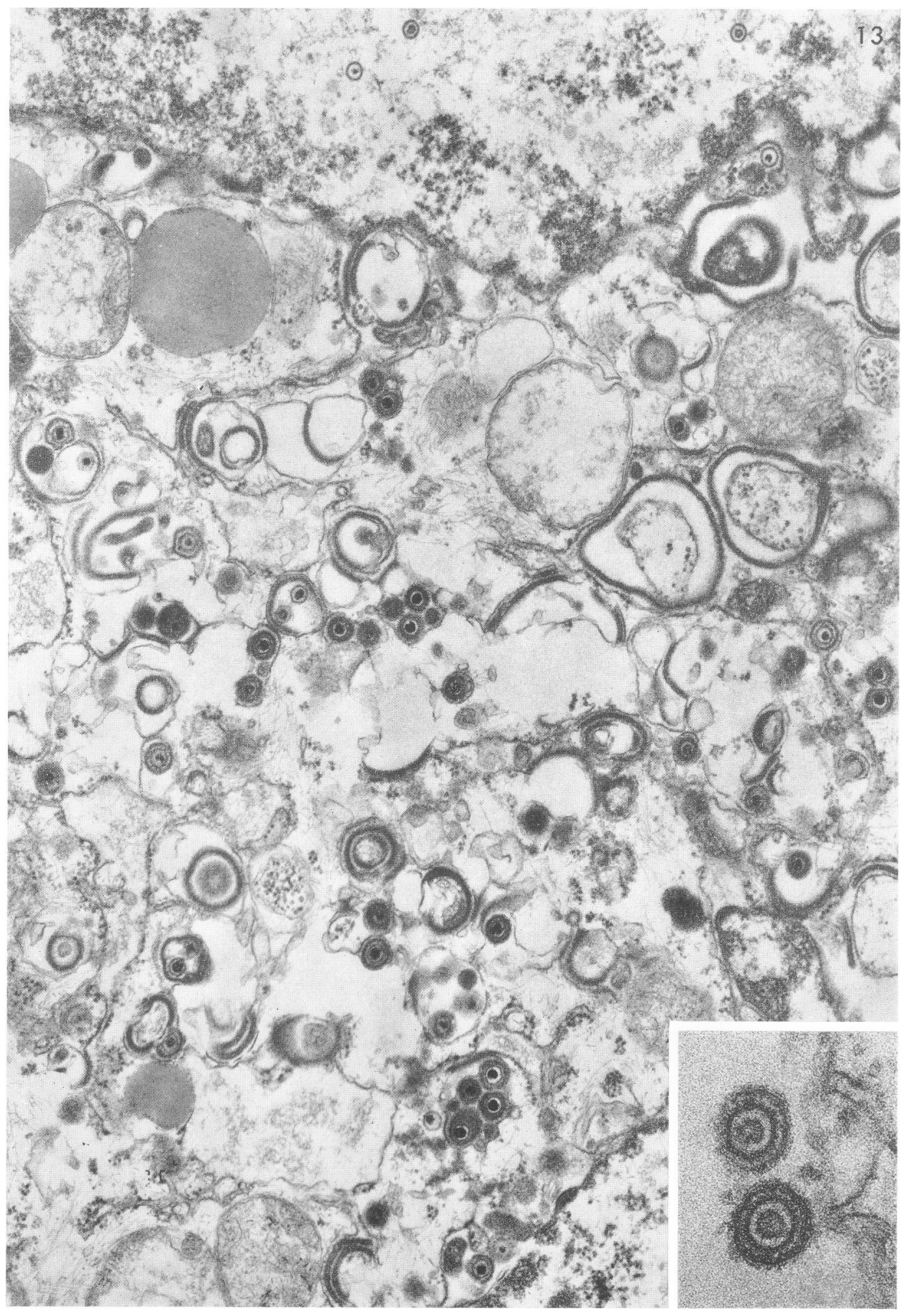

FIG. 13. Part of the cytoplasm and nucleus of a cell which was blocked and then released. Characteristic virus is evident. $\times$ 50,000. Inset: two extracellular viral particles with cores of low density. $\times 90,000$. 
Whether such transport is controlled by progeny DNA, as could be inferred by the presence of capsids with cores of low density in the cytoplasm only of cells treated with $\mathrm{HU}$, must await further investigation.

The present observations, when combined with those described earlier (10), suggest the following sequence of events for normal viral development. The synthesis of early proteins and their assembly into capsids and cores of low density precede, and are independent of, synthesis of progeny DNA. The subsequent production of progeny DNA is associated with the appearance of dense cores. The capsids containing dense cores are selectively transported to the cytoplasm, during which process most of them become enveloped. Finally, it may be postulated that the envelopment of capsids and their passage into the cytoplasm occurs quickly, first, because stages in these processes are rarely visualized, and, second, because enveloped virus in the cytoplasm is usually encountered as soon as dense cores in the nucleus are seen.

\section{ACKNOWLEDGMENTS}

This investigation was supported by Public Health Research grant AI-06814 from the National Institute of Allergy and Infectious Diseases. Support was also provided by United States Public Health Service grant CA-08374 from the National Cancer Institute. H. S. Rosenkranz is a Research Career Development Awardee of the National Institute of General Medical Sciences, United States Public Health Service (5-K3GM-29,024).

\section{Literature Cited}

1. De Sousa, C. P., E. Boyland, and R. Nery. 1965. Inhibition of Shope fibroma virus with $\mathrm{N}$ hydroxyurethane and related compounds. Nature 206:688-689.

2. Ellison, S. A., and H. S. Rosenkranz. 1963. An apparatus for sampling after cesium chloride density gradient centrifugation in the preparative ultracentrifuge. Anal. Biochem. 5:263-265.

3. Gale, G. R. 1964. Effect of hydroxyurea on the incorporation of thymidine into Ehrlich ascites tumor cells. Biochem. Pharmacol. 13:13771382.

4. Kihlman, B. A., T. Eriksson, and G. Odmark. 1966. Effects of hydroxyurea on chromosomes, cell division, and nucleic acid synthesis in Vicia faba. Hereditas 55 :386-397.
5. Levitt, J., and Y. Becker. 1967. The effect of cytosine arabinoside on the replication of herpes simplex virus. Virology $31: 129-134$

6. Levy, J. A., R. J. Huebner, J. Kern, and R. V. Gilden. 1968. High titre $T$ antigen with minimal amounts of structural antigen in adenovirusinfected cells treated with hydroxyurea. Nature 217:744-745.

7. Margaretten, W., C. Morgan, H. S. Rosenkranz, and H. M. Rose. 1966. Effect of hydroxyurea on virus development. I. Electron microscopic study of the effect on the development of bacteriophage T4. J. Bacteriol. 91 :823-833.

8. Morgan, C., H. M. Rose, and B. Mednis. 1968. Electron microscopy of herpes simplex virus. I. Entry. J. Virol. 2:507-516.

9. Nii, S., and J. Kamahora. 1961. Cytopathic changes induced by herpes simplex virus. Biken's J. 4:51-58

10. Nii, S., C. Morgan, and H. M. Rose. 1968. Electron microscopy of herpes simplex virus. II. Sequence of development. J. Virol. 2:517536.

11. Pollak, R. D., and H. S. Rosenkranz. 1967. Metabolic effects of hydroxyurea on BHK 21 cells transformed with polyoma virus. Cancer Res. 27:1214-1224.

12. Roizman, B., and P. R. Roane. 1964. The multiplication of herpes simplex virus. II. The relation between protein synthesis and the duplication of viral DNA in infected HEp-2 cells. Virology $22: 262-269$.

13. Rosenkranz, H. S., A. J. Garro, J. A. Levy, and H. S. Carr. 1966. Studies with hydroxyurea. I. The reversible inhibition of bacterial DNA synthesis and the effect of hydroxyurea on the bactericidal action of streptomycin. Biochim. Biophys. Acta $114: 501-515$.

14. Rosenkranz, H. S., and J. A. Levy. 1965. Hydroxyurea: a specific inhibitor of deoxyribonucleic acid synthesis. Biochim. Biophys. Acta 95:181-183.

15. Rosenkranz, H. S., H. M. Rose, C. Morgan, and K. C. Hsu. The effect of hydroxyurea on virus development. II. Vaccinia virus. Virology 28: 510-519.

16. Rosenkranz, H. S., E. B. Winshell, A. Mednis, H. S. Carr, and C. J. Ellner. 1967. Studies with hydroxyurea. VII. Hydroxyurea and the synthesis of functional proteins. J. Bacteriol. 94:1025-1033.

17. Young, C. W., and S. Hodas. 1964. Hydroxyurea: inhibitory effect on DNA metabolism. Science 146:1172-1174. 